\title{
Influence of Pedestrian Trajectories on School Children Exposure to $\mathbf{P M}_{10}$
}

\author{
João Garcia, ${ }^{1}$ Rita Cerdeira, ${ }^{1}$ Luís Coelho, ${ }^{1}$ \\ Prashant Kumar, ${ }^{2,3}$ and Maria da Graça Carvalho ${ }^{4}$ \\ ${ }^{1}$ Escola Superior de Tecnologia de Setúbal, Instituto Politécnico de Setúbal, Campus do IPS, 1910-761 Setúbal, Portugal \\ ${ }^{2}$ Department of Civil and Environmental Engineering, Faculty of Engineering and Physical Science (FEPS), \\ University of Surrey, GU2 7XH, UK \\ ${ }^{3}$ Environmental Flow (EnFlo) Research Centre, FEPS, University of Surrey, GU2 7XH, UK \\ ${ }^{4}$ Instituto Superior Técnico, Avenida Rovisco Pais 1, 1049-001 Lisboa, Portugal
}

Correspondence should be addressed to João Garcia; joao.garcia@estsetubal.ips.pt

Received 31 March 2014; Revised 10 June 2014; Accepted 18 June 2014; Published 22 July 2014

Academic Editor: Godwin Ayoko

Copyright (C) 2014 João Garcia et al. This is an open access article distributed under the Creative Commons Attribution License, which permits unrestricted use, distribution, and reproduction in any medium, provided the original work is properly cited.

\begin{abstract}
Three pedestrian trajectories are considered to study the influence of $\mathrm{PM}_{10}$ concentrations on children exposure, in a high-traffic street canyon. Two types of exposure were calculated: daily exposure for each wind condition and cumulative annual exposure considering all wind conditions. FLUENT was used to simulate the flow, turbulence, and $\mathrm{PM}_{10}$ dispersion in the street canyon. Our results indicate that exposure is influenced by the chosen walking trajectory and wind direction. When considering daily exposure, the highest value is achieved for the trajectory on the south side of the street, under westerly wind conditions, $13 \%$ higher than the baseline that assumes no traffic. The results indicate that a particular trajectory can be better for one specific wind direction but can represent the worst for a different wind direction. A difference of $3 \%$ to $13 \%$ higher exposure was achieved by choosing the best and worst trajectories. When computing cumulative annual exposure, trajectory on the north side of the street shows better results, $8.4 \%$ higher than the baseline value. Northerly and westerly winds result in the lowest and the highest exposure value for every studied trajectory. Careful selection of the best pedestrian paths can help reduce the exposure in busy street canyons.
\end{abstract}

\section{Introduction}

Air quality in city environments is a matter of increasing interest due to its direct impact on the public health [1]. In the last decades, traffic-related air pollution and health problems have increased, especially in children during their scholar age [2]. Children's bodies are still under development during this age, making their airways, alveoli, and immunity systems more vulnerable to diseases [3]. Furthermore, children inhale more air per kilogram of body weight than adults due to their increased breathing rates [4-6]. It is now accepted that air pollutants can trigger allergies and respiratory problems, particularly in children with chronic respiratory diseases [7]. However, this is a complex issue since it is not easy to confer causes to some respiratory diseases such as asthma and bronchitis due to the limited understanding on cellular and molecular levels. This issue is further complicated by the complex temporal and spatial pattern of human exposure to air pollution $[8,9]$. The fact that the intervenient factors can interact between themselves, the relation between pollutant concentrations and health is even more complex [10]. Longterm exposure to low level concentrations of air pollutants, sometimes even below legislation limits, can also have significant health impacts [8]. These issues make the concentration of particulate matter (PM) in urban street canyons one of the major air pollution issues.

PM is a complex mixture of solid and liquid particles that are made of organic and inorganic substances [11]. Numerous scientific studies have correlated exposure to PM in air pollution, showing a number of health issues. These include increased respiratory problems, such as respiratory irritation, coughing, or difficulty in breathing $[10,12]$, reduction of 
pulmonary function [13-15], development of chronic bronchitis [16] but also those not associated with the respiratory tract, such as the development of irregular heartbeat [17, 18], appearance of non-fatal heart attacks [19], and even premature death in people with heart or lung disease [20].

Particular attention has been paid to $\mathrm{PM}_{10}$ and $\mathrm{PM}_{2.5}$ among other pollutants, considering their adverse impacts on human health $[2,21]$, and more recently studies have started including nanoparticles in their assessments [22] especially considering the importance of nanoparticles from road traffic emission $[23,24]$, although most epidemiological studies are focused on $\mathrm{PM}_{10}$ and $\mathrm{PM}_{2.5}$ and there are certain evidences that short-term exposure to high concentrations of $\mathrm{PM}_{10}$ can aggravate pulmonary diseases and influence paediatric asthma and some studies suggest that long-term exposure to low concentrations on $\mathrm{PM}_{10}$ may increase the risk of both the cardiovascular and pulmonary diseases [25].

The objective of this paper is to study the influence of chosen pedestrian paths by the school children on their exposure to $\mathrm{PM}_{10}$ in a selected street canyon in Barreiro city, Portugal. The chosen canyon carries high traffic volume and form part of a main route for local children to reach to a school. Three different school walk children pedestrian trajectories are considered in a selected street canyon and the impact of chosen pedestrian paths on children exposure is computed considering four specific wind directions that prevail across the whole year.

\section{Characterization of Studied Domain}

2.1. The Study Site. The study is carried out in Bocage avenue in Barreiro city. Barreiro is a medium sized city, which is located $40 \mathrm{~km}$ south of Lisbon in Portugal. This has 34 $\mathrm{km}^{2}$ area and about 80000 inhabitants. The main industrial activity is chemical factory located near the city centre, and the city has important suburb car traffic fluxes. The city is almost flat, with its highest point at approximately $10 \mathrm{~m}$ above sea level. The weather is temperate, with no severe seasons. Bocage avenue, where the school is located, is a strategic key point, connecting the city centre with a highway to Lisbon. The traffic flux is high ( 2900 vehicles per hour) during the rush hours, representing the main source of pollution in the street canyon.

2.2. The Emissions. Presently the main emission sources in Barreiro city are due to road traffic. In the past, the city also had an important chemical industry, but this industry does not operate within the city currently. There is a natural gas power plant but it works very sporadically and its emissions have no direct impact on the studied street canyon due to the located distance $(\sim 2.5 \mathrm{~km})$ due to predominant wind direction. These emissions contribute to background emission during favourable wind directions. Therefore, traffic is the major pollutant source in the studied street canyon. Light duty vehicles (LDV) constitute $\sim 90 \%$ of total traffic volume. The proportion of heavy duty vehicles (HDV) is only $\sim 2 \%$ of the total traffic volume. To evaluate the PM emissions from road traffic, a traffic characterization campaign was carried out in the studied street canyon. This characterised number of vehicles in four different types (e.g., LDV, HDV, motorcycles, and buses) and their speeds and type of fuel used by these vehicles.

2.3. Meteorological Conditions. Meteorological data was used from the official Portuguese Climatological network managed by Instituto de Meteorologia (IM) from the nearest weather station (Lavradio), which is $\sim 2 \mathrm{~km}$ away from the study area. Official data available from years 1967-1990 was used. For the purpose of the study, wind conditions were grouped in four main directions-north, east, south, and west-related to the cross-canyon and along-canyon wind directions. The prevailing wind direction was found to be west (W) with frequency as $41.4 \%$ (see Figure 1 ). The highest wind speed $(12.4 \mathrm{~km} / \mathrm{h})$ corresponded to the prevailing direction $\mathrm{W}$, which was frequent during the summer months (June, July, and August), with the maximum (58.5\%) and minimum (15.6\%) occurrences being in August and December, respectively.

2.4. The Studied Route to School. The pedestrian pathway of school children considered the ones reflecting the children walking trajectories when going to and coming back from primary school considering the most used pedestrian pathway observed in the street canyon (see Figure 6). This school is located along the Bocage avenue. The south facade of the school is located on Bocage avenue which is an important heavy-traffic road used by the children to reach to school (Figure 2). This elementary school is attended by $\sim 120$ children from 1-10 years old. The school schedule operates from 09:00 to 12:00 $\mathrm{h}$ (local time) in the morning and from 13.15 to $15.15 \mathrm{~h}$ in the afternoon. The school consists of two buildings, each having two floors above the ground level.

\section{Materials and Methods}

3.1. Development of an Integrated Analysis Structure. Considering the number of variables involved in analysis such as the meteorological data, traffic counting and emissions, CFD, and ADMS modelling, an integrated approach to deal with them is developed (see Figure 3). This structure considers the atmospheric wind profile resulting from weather conditions and emissions from urban traffic in the street. The study domain was initially drawn with the AutoCAD software, where Bocage avenue is represented three-dimensionally (3D) with its buildings. This 3D design is subsequently exported to ANSYS Workbench [26] where the boundaries and mesh size are defined. These data are then used by the Fluent where the mesh is verified; boundary conditions and turbulence models are set. Fluent receives data from traffic emission rates calculated by the ADMS-Urban model [27]. These traffic emission rates are based on the input received from the traffic counting system, especially designed for this application. In Fluent, the convergence criteria are defined, the solution is initialized, and the calculations are performed. After having achieved convergence calculations all results are 


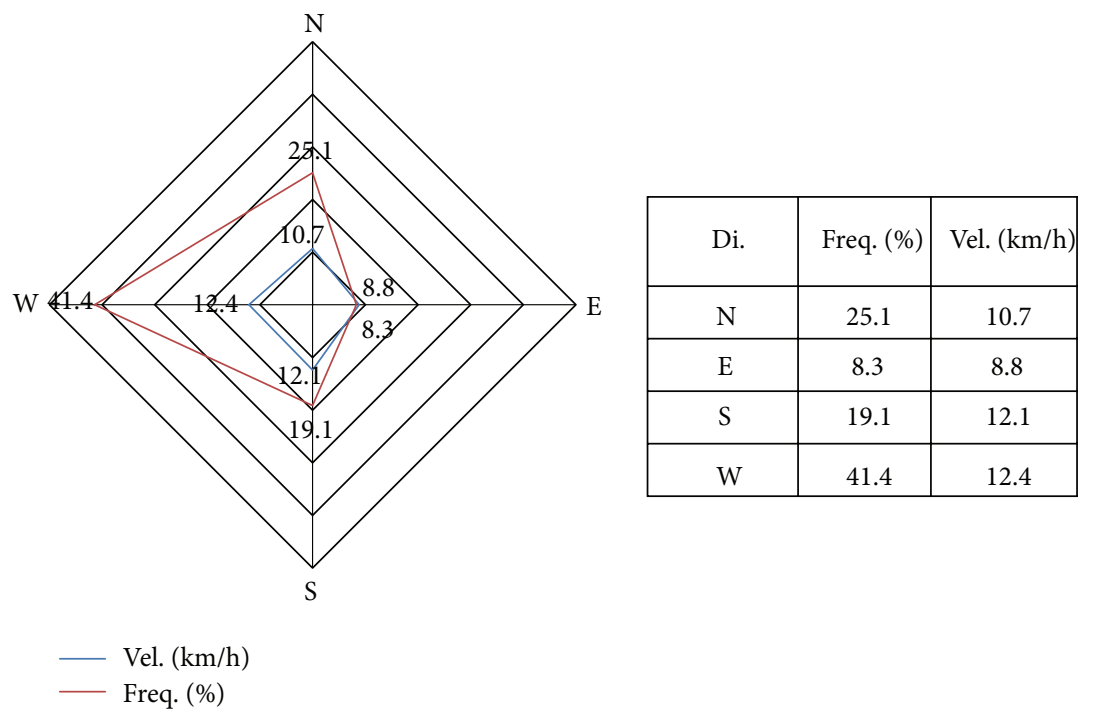

Figure 1: Summary of four main directions seen through a wind rose and a table.

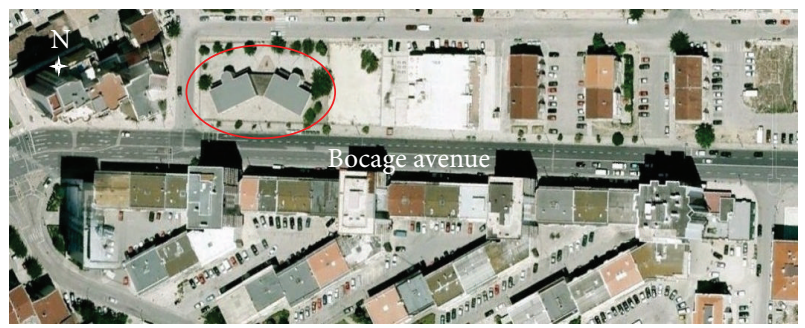

FIGURE 2: Location of school in the street canyon.

transferred to the CFD Post (postprocessor) where the results are displayed.

3.2. The Traffic Counting System. Since road traffic is the major source of pollutants in the studied street canyon, a traffic counting system was designed, developed, and implemented for the detailed characterization of traffic volume so that the PM emissions can be estimated adequately. This system counts vehicles moving along the road, identifies the type of vehicle, and calculates the vehicle running speed. This system consists of two Omron photocells long distance retroreflective Model E3G-L73 2M [28], an Omron PLC (programmable controller) CP1L, a HP laptop, and a software programme specially developed for this purpose. The traffic counting system implemented in the street is shown in Figure 4 .

The traffic counting was carried out during three periods: 08:00-10:00 h (local time), 12:00-13:00, and 17:00-20:00 h (local rush hours) during the three days of field campaigns. The vehicles counting were carried out for one hour in each period. The vehicles were classified according to four different classes (LDV, HDV, buses, and motorcycles). All this information was provided as an input to the ADMS-Urban model to calculate $\mathrm{PM}_{10}$ emission rates (CERC, 2006).
3.3. $\mathrm{PM}_{10}$ Concentration Measurements Campaign. $\mathrm{PM}_{10}$ concentrations were measured during a field campaign, performed at Avenida do Bocage street, from 17 to 20 October 2011 during the day time between $0900 \mathrm{~h}$ and $1800 \mathrm{~h}$ (local time). The DustTrack model 8520 was used for the $\mathrm{PM}_{10}$ measurements. The sampler uses a suction pump to take the flow of $1.7 \mathrm{~L} \mathrm{~min}^{-1}$ through an optical chamber where the sample is backlighted with a laser beam and the particles reflect this light that is read by a photo detector. The detection circuit converts the light into voltage that is proportional to the mass concentration of $\mathrm{PM}_{10}$. Measurements were made at 7 different points that were $1.5 \mathrm{~m}$ above the ground level along the canyon length to gain the representative values. The average ambient temperature and relative humidity during the measurement campaigns were $25^{\circ} \mathrm{C}$ and $40 \%$, respectively. Predominant wind direction was noted as "west" (i.e., along the street canyon). These data were validated by the air quality data available from the stations from the governmental Portuguese Air Quality Network managed by CCDR-LVT.

3.4. The CFD Model. CFD simulations were carried out using ANSYS Fluent 12.0 [26] for finding the dispersion of $\mathrm{PM}_{10}$ in the selected street canyon [29]. This is a multipurpose commercial software, widely used and constantly validated through comparison of results with dispersion models [30] or wind tunnel experiments [31]. The geometry of the street is shown in Figure 5 and the simulations were carried out for the four main wind directions.

The simplified computational domain for the chosen street canyon has length, breadth, and height as 715, 300, and $150 \mathrm{~m}$, respectively, for the westerly and easterly wind directions. A tetrahedral unstructured grid was used for the spatial discretisation of the computational domain, which was refined near the buildings. ANSYS Workbench software [29] was used for the construction of the grid. The smallest grid size was kept $1 \mathrm{~m}$ close to the walls of buildings. This grid size increased with the distance from the walls, using 


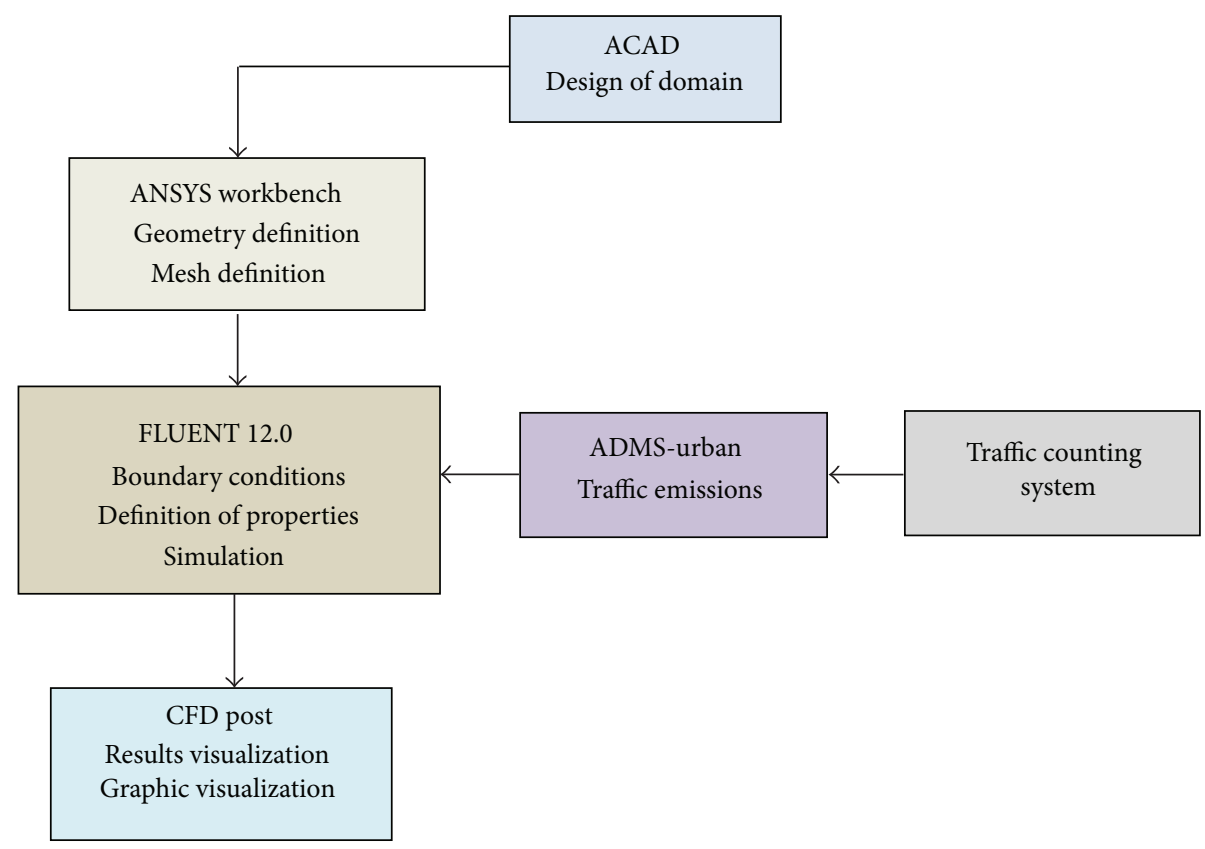

FIGURE 3: The architecture of the integrated analysis structure.

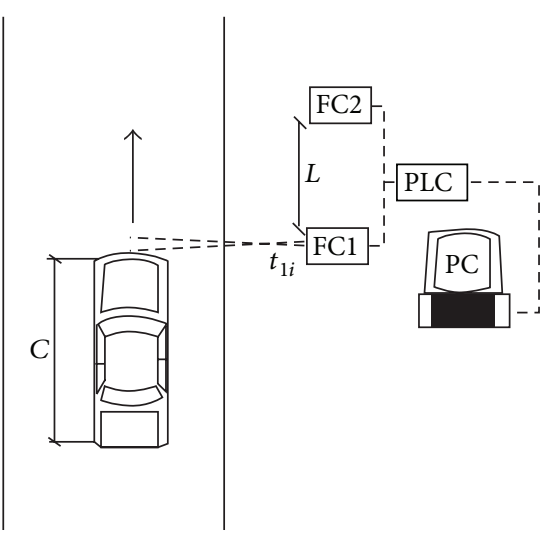

(a)

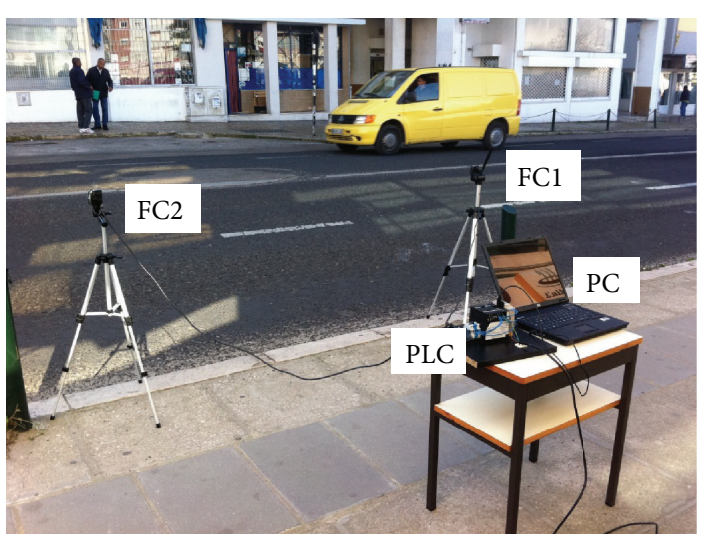

(b)

FIGURE 4: The road traffic counting system implemented in the street.

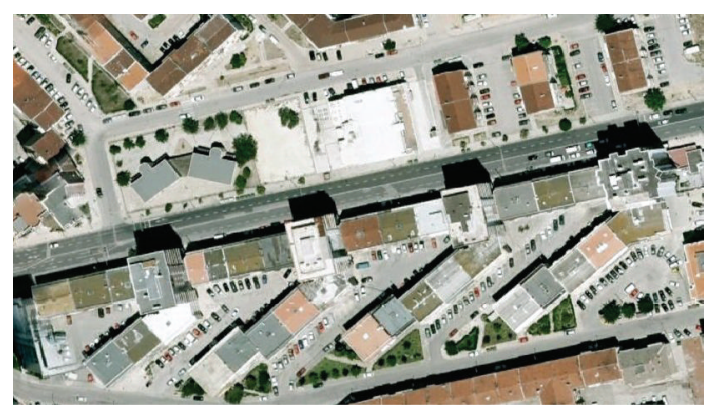

(a)

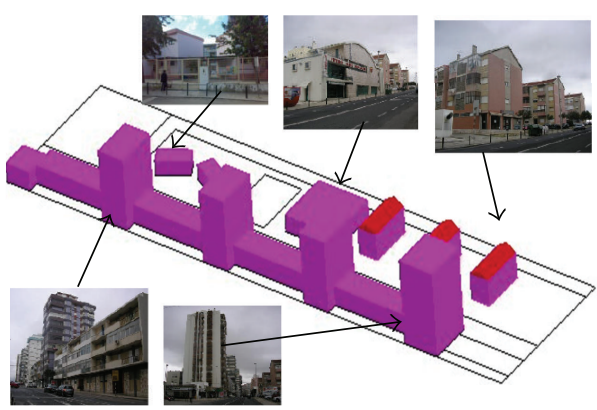

(b)

FIGURE 5: Schematic of the real street and its CFD model. 
an expansion factor equal to 1.2. The domain included a total of 201354 cells and 37303 nodes for the west wind direction. For the winds from the north and south the domain has length, breadth, and height as 491, 524, and $150 \mathrm{~m}$, respectively. A mesh sensitivity analysis was made to verify the independence of the solution, following the COST 732 guidelines [32], to confirm that the prediction result does not change significantly with different grid systems. An Eulerian approach was applied for the simulation of 3D flow, assuming steady-state conditions. For the turbulence closure, a RNG ke model was used that calculated 3D fields of wind, turbulent viscosity, pressure, and turbulence. For the $\mathrm{PM}_{10}$ dispersion, a Lagrangian approach was used for the computation of the 3D concentration field. The dispersion model consists of a second phase of spherical particles in a Lagrangian frame of reference, dispersed in the continuous phase with coupling between the phases. The initial position, velocity, and size of particles were introduced, and the stochastic tracking considered was the discrete random walk model. Atmospheric conditions were assumed as neutral. The RNG k-e turbulence model was adopted that provided an analytical formula for turbulent Prandtl numbers. In terms of boundary conditions, a no-slip condition was imposed at all solid surfaces. At the top of domain a symmetry boundary was considered, assuming a zero flux of all quantities across the horizontal plane. At the inlet, a logarithmic vertical wind profile was adopted, based on the local measurement campaigns. The wind profile, turbulent kinetic energy, and turbulence dissipation rate were introduced using the following formulation:

$$
U_{y}=\frac{u^{*}}{\kappa} \ln \left(\frac{y+y_{0}}{y_{0}}\right)
$$

where $U_{y}\left(\mathrm{~m} \mathrm{~s}^{-1}\right)$ is the wind velocity at height, $y ; \kappa(=0.42)$ is the Von Karman constant; $y_{0}(\mathrm{~m})$ is the aerodynamic roughness length of the ground; $u^{*}\left(\mathrm{~m} \mathrm{~s}^{-1}\right)$ is the friction velocity [33]:

$$
u^{*}=\frac{\kappa U_{10}}{\ln \left(\left(10+y_{0}\right) / y_{0}\right)},
$$

where $U_{10}\left(\mathrm{~m} \mathrm{~s}^{-1}\right)$ is the wind velocity at $10 \mathrm{~m}$ height. The turbulent kinetic energy, $\varepsilon\left(\mathrm{m}^{2} \mathrm{~s}^{-2}\right)$, and turbulence dissipation rate, $k\left(\mathrm{~m}^{2} \mathrm{~s}^{-2}\right)$, at the inlet is estimated using

$$
\varepsilon=\frac{u_{*}^{3}}{\kappa\left(y+y_{0}\right)}, \quad k=3.33 u_{*}^{2} .
$$

$\mathrm{PM}_{10}$ emission rates were calculated by the model ADMSUrban, considering the traffic counting described in Section 3.2. No chemical reactions were considered for $\mathrm{PM}_{10}$ emissions. The emissions were introduced in Fluent as line sources and considering the mean traffic number of vehicles in rush hours as the baseline scenario for traffic emissions. The other emissions considered in the domain were introduced as background concentrations that were added to Fluent results. The value for background concentrations was collected from the Fidalguinhos Air Quality Station from the Portuguese AQ system; this station is classified as an urban

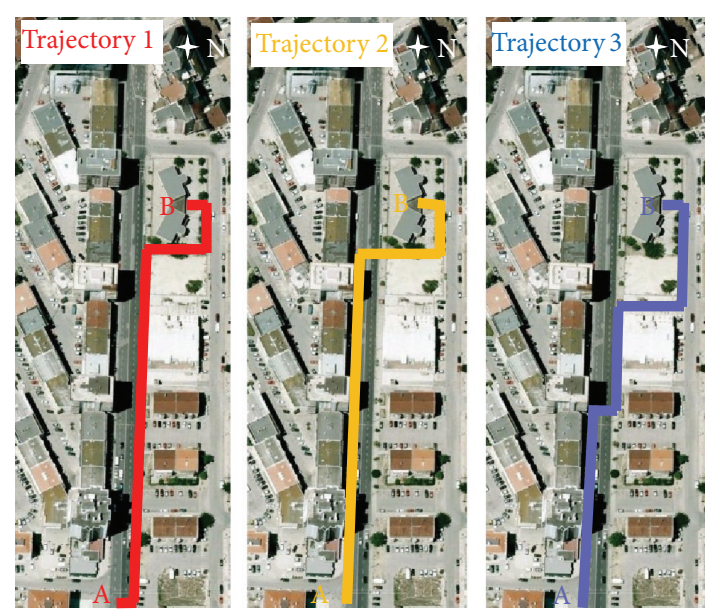

FIGURE 6: The three children pedestrian trajectories considered for the study.

background station. The model validation was made using the real measurements of $\mathrm{PM}_{10}$ concentrations made in the Bocage street and described in Section 3.3. Further details on the boundary conditions, study domain, the input conditions modelling details regarding the CFD simulations, and the air quality measurements can be found in Garcia et al. [29].

\subsection{Estimation of Children Exposure on Pedestrian Trajecto-} ries. Three different pedestrian trajectories inside the street canyon, between points $\mathrm{A}$ and $\mathrm{B}$, showing entrance of the street and school, respectively, were considered as a walking path for children to and from the school (Figure 6). All the three trajectories (namely, 1, 2, and 3) have the same distance of $300 \mathrm{~m}$ (see Table 1). The purpose is to study the influence of the walking trajectory on the $\mathrm{PM}_{10}$ exposure to children during the four different wind directions. To simplify computations, wind conditions were grouped in the four main directions (N, S, E, and $\mathrm{W})$.

Personal exposure $E(\Delta t)$ in a period of time $(t)$ can be estimated using (4) given by $[34,35]$

$$
E(\Delta t)=\int_{0}^{t} C(t) d t \cong \sum_{i}^{n} C_{i} t_{i},
$$

where $C(t)$ is the pollutant concentration $\left(\mu \mathrm{g} / \mathrm{m}^{3}\right)$ in a period of time $t, C_{i}\left(\mu \mathrm{g} \mathrm{m}^{-3}\right)$ is the discrete concentration in cell $i$ and $t_{i}$ (seconds) is time of exposure in cell $i$, and $n$ is the number of exposure cells.

In order to calculate the exposure related with each of the three pedestrian trajectories, the computational domain was discretized in a grid with 240 cells that had 279 nodes, each one correspondent to $10 \mathrm{~s}$ time walk trajectory (see Figure 7). The children exposure $(E)$ was calculated in the cells corresponding to pedestrian trajectories considered.

\section{Results}

4.1. $P M_{10}$ Concentrations. Figure 8 shows the $\mathrm{PM}_{10}$ concentration results from the CFD simulations during the four 
TABLE 1: Details of the three pedestrian trajectories considered.

\begin{tabular}{|c|c|c|c|c|}
\hline Pedestrian trajectory & Description of trajectory & $\begin{array}{l}\text { Total walking distance } \\
(\mathrm{m})\end{array}$ & $\begin{array}{l}\text { Walking mean velocity } \\
(\mathrm{m} / \mathrm{s})\end{array}$ & $\begin{array}{c}\text { Total time } \\
(\mathrm{s})\end{array}$ \\
\hline 1 & Bocage Av-north side & 300 & 1.0 & 300 \\
\hline 2 & Bocage Av-south side & 300 & 1.0 & 300 \\
\hline 3 & Bocage Av-south then north & 300 & 1.0 & 300 \\
\hline
\end{tabular}

TABLE 2: Summary of modelled $\mathrm{PM}_{10}$ concentrations at $1.5 \mathrm{~m}$ height above the ground level in studied street canyon.

\begin{tabular}{|c|c|c|c|c|c|c|}
\hline \multirow{2}{*}{ Designation } & \multirow{2}{*}{ Location } & \multicolumn{4}{|c|}{$\mathrm{PM}_{10}\left(\mu \mathrm{g} \mathrm{m}^{-3}\right)$} & \multirow{2}{*}{$\mathrm{CW}\left(\mu \mathrm{g} \mathrm{m}^{-3}\right)$} \\
\hline & & West wind & North wind & South wind & East wind & \\
\hline Point 1 & School & 21.6 & 21.2 & 20.7 & 22.3 & 21.3 \\
\hline Point 2 & Bingo & 23.0 & 28.6 & 27.1 & 27.0 & 25.4 \\
\hline Point 3 & Car park (border) & 20.1 & 20.0 & 20.1 & 20.0 & 20.1 \\
\hline Point 4 & Car park (middle) & 20.4 & 20.0 & 20.1 & 20.0 & 20.2 \\
\hline Point 5 & High building corner & 20.5 & 20.6 & 22.7 & 20.0 & 20.9 \\
\hline Point 6 & Resid. building (east) & 22.2 & 21.5 & 21.9 & 21.0 & 21.7 \\
\hline Point 7 & Resid. building (west) & 25.0 & 20.9 & 22.5 & 20.7 & 22.8 \\
\hline Mean value & $1.5 \mathrm{~m}$ plane (all domain) & 20.8 & 20.5 & 21.0 & 21.1 & - \\
\hline
\end{tabular}

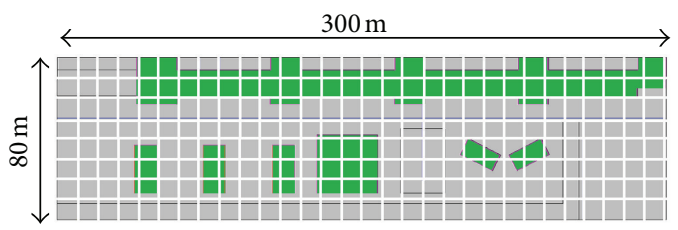

FIGURE 7: The discrete grid used in exposure calculations.

different wind directions. Contour plots of $\mathrm{PM}_{10}$ concentrations are plotted for a breathing height of $1.5 \mathrm{~m}$ [36]. Simulated $\mathrm{PM}_{10}$ results were compared and validated with the real $\mathrm{PM}_{10}$ measurements obtained from the field campaigns described in Section 3.3. This comparison showed the following relative errors $-8.9 \%$ average, $6.0 \%$ median, and $18.6 \%$ maximum - between the measured and modelled data at the 7 representative points. Detailed description of this validation can be found in Garcia et al. [29]. Please note that only traffic emissions are considered in Figure 8 and no background concentrations are added, but Table 2 shows the sum of both traffic and background contributions. The total concentrations are shown for seven points 1-7 that are located in the street canyon (see Figure 8). The point corresponding to the studied school is identified as point 1 . Additionally it is shown that the overall mean concentration value at a plane is located at $1.5 \mathrm{~m}$ above the ground level. The mean weighted concentration (CW) is estimated using (5), which is the product of mean concentration and the wind direction frequency $\left(f_{i}\right)$. This allows evaluating cumulative
$\mathrm{PM}_{10}$ concentration for one year considering different wind directions:

$$
\mathrm{CW}=C_{\mathrm{PM}_{10}} \times f_{i},
$$

where $C_{\mathrm{PM}_{10}}$ is the concentration of $\mathrm{PM}_{10}$ in $\mu \mathrm{g} / \mathrm{m}^{3}$ and $f_{i}$ is the frequency of wind direction, which is $25.1 \%$ for north, $8.3 \%$ for east, $19.1 \%$ for south, $41.4 \%$ for west, and $6.1 \%$ for calm.

The simulation results show that the highest value of $\mathrm{PM}_{10}$ concentration (hot spot) is achieved at point 2 (Bingo building) with a value of $28.6 \mu \mathrm{g} \mathrm{m}^{-3}$ for northerly winds. This point is located on the north end of the road near the widest building on this side, making it difficult for the upstream wind to carry the pollutant outside the street canyon. This point also corresponds to the highest $\mathrm{CW}$ value considering the concentrations and wind direction frequencies. If we consider the mean value of concentrations at $1.5 \mathrm{~m}$ plane for the entire domain, the highest value is achieved for easterly winds with a mean value of $21.1 \mu \mathrm{g} \mathrm{m}^{-3}$. The model accuracy discussed previously in this section shows no significant differences for all considered directions. It is also visible that all these values are however below the daily and annual national limits for $\mathrm{PM}_{10}$ in Portugal, which are 50 and $40 \mu \mathrm{g} \mathrm{m}^{-3}$, respectively.

\subsection{Children Exposure during Different Wind Directions.} Table 3 shows the daily exposure results for children for the three considered trajectories (1,2, and 3) under the four different wind directions. The values were normalized by the baseline children exposure value. The base line corresponds 


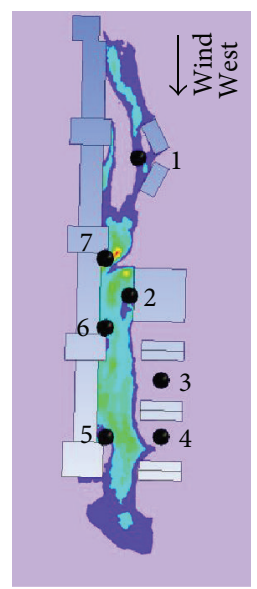

(a)

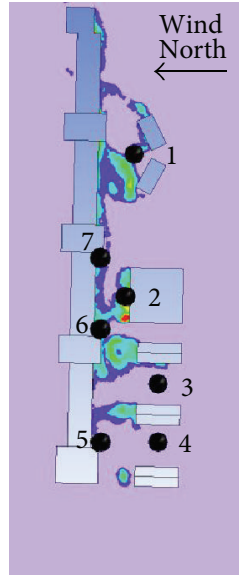

(b)

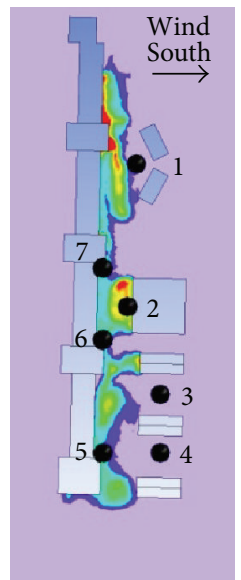

(c)

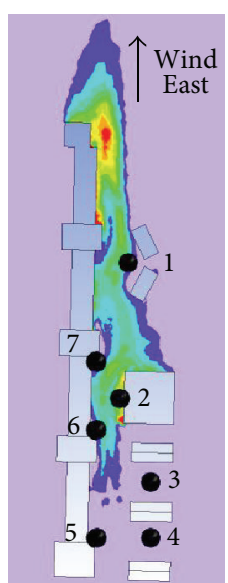

(d)

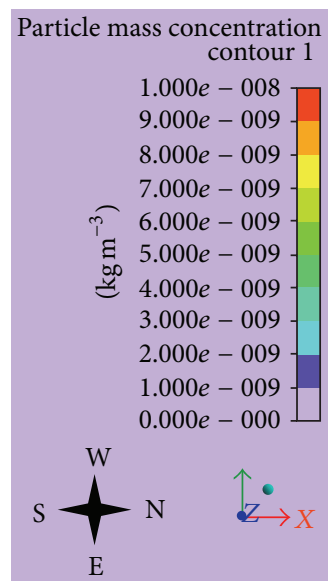

(e)

FIGURE 8: Contour plots of $\mathrm{PM}_{10}$ concentrations at $1.5 \mathrm{~m}$ above the road level in studied street canyon during four different wind directions.

TABLE 3: Daily children trajectory exposure to $\mathrm{PM}_{10}$ for the three scenarios considered.

\begin{tabular}{lcccc}
\hline Children & \multicolumn{4}{c}{ Non dimensionless exposure } \\
Trajectory & W-winds & N-winds & S-winds & E-winds \\
\hline 1 & 1.11 & 1.07 & 1.10 & 1.10 \\
2 & 1.13 & 1.03 & 1.09 & 1.06 \\
3 & 1.08 & 1.06 & 1.12 & 110 \\
\hline
\end{tabular}

to a trajectory inside the street canyon with the same length $(300 \mathrm{~m})$ and the same walking duration (300 s), assuming that there is no traffic in the street and the exposure is only to background $\mathrm{PM}_{10}$ concentration which is taken as $20 \mu \mathrm{g} \mathrm{m}^{-3}$ [37].

Interestingly, both the lowest (3\%) and the highest (13\%) values for children exposure are achieved by trajectory 2 under northerly (cross-canyon) and westerly (along-canyon) winds, respectively, compared with the baseline values. These results show that one trajectory can be the best for one wind direction but can be the worst for another wind direction. The results also show that cross-canyon winds favour the reduced children exposures, showing much lower exposure among all the three trajectories considered. One of the reasons are that the cross-canyon wind conditions disfavours the hot-spot generation (point 2 referred in Table 2), as seen in Figure 8. Overall, trajectory 2 is the best one for north, south, and east wind conditions, except westerly winds where trajectory 3 provides the minimum exposure.

4.3. Children Exposure over the Full Academic Year. In order to consider children exposure in a complete year, due to mobility to and from the school, exposure is estimated considering the variability (frequency) of wind direction, $f_{i}$, across the whole academic year. The results were also normalized by the baseline children exposure value, explained in Section 4.2. The results are given by the nondimensional
TABLE 4: Normalised children trajectory exposure to $\mathrm{PM}_{10}$ for the four trajectories considering wind direction frequency for one year.

\begin{tabular}{lc}
\hline $\begin{array}{l}\text { Pedestrian } \\
\text { trajectory }\end{array}$ & Normalised exposure \\
\hline 1 & 1.095 \\
2 & 1.088 \\
3 & 1.084 \\
\hline
\end{tabular}

parameter $(E)$, as shown in the following:

$$
E_{y i}=\frac{C_{i} \times t_{i} \times f_{i}}{E_{\text {baseline }}},
$$

where $E_{y i}$ is nondimensional annual average children trajectory exposure due to trajectory $i$ (all year) and $C_{i}$ is the concentration of $\mathrm{PM}_{10}\left(\mu \mathrm{g} \mathrm{m}^{-3}\right)$ in the cell, $i$; $t_{i}$ is the permanency time in cell (s); and $f_{i}$ is the wind direction frequency for one year, as discussed in Section 4.1. Table 4 shows results for nondimensional total year children pathway exposure due to trajectory $i$ (sum of going to and returning from school) for the three trajectories (1,2, and 3$)$.

Trajectory 3 , which shows the lowest children exposure value that is only $\sim 8.4 \%$ higher than the baseline children exposure, emerges as a best choice for children exposure. These findings enforce our previous conclusions that one particular trajectory can be the best for one specific wind direction, but when considering the all year conditions the best trajectory for children exposure can be different.

\section{Conclusions}

An integrated exposure assessment approach was developed to study the influence of pedestrian trajectories on the exposure of $\mathrm{PM}_{10}$ to school children in street canyon environments. The approach considered a fully automatic system for the analysis of traffic profiles, a tool for calculation of traffic emissions (ADMS-Urban), and a CFD model (ANSYS 
Fluent) to simulate the dispersion of $\mathrm{PM}_{10}$ inside the street canyon. The level of personal exposure to $\mathrm{PM}_{10}$ for school children walking inside the street canyon towards the school was calculated considering the three different trajectories. The results show that the children exposure in the street canyon is dependent on the wind directions. The highest value for children trajectory exposure is achieved for one specific trajectory (2) under along-canyon wind conditions, showing up to $13 \%$ higher exposure than the baseline case (assuming no traffic conditions). Interestingly, the lowest value (3\%) for children exposure is also achieved for the same trajectory (2) during the cross-canyon winds. These results show that considering one wind direction a trajectory can be the best choice, but the same trajectory can be the worst choice from an exposure point of view under a different wind directions.

Results also show that for this specific street, crosscanyon wind conditions are generally better for exposure than the along-canyon wind conditions. This is due to the better mixing of the $\mathrm{PM}_{10}$ during cross-canyon winds. When compared with a baseline trajectory, with no traffic in the street, a variation between 3\% and 13\% higher exposure was found by choosing a trajectory under a specific wind direction. Results show that the best trajectory can be different than the best choice trajectory of one particular moment when considering exposure based on annual averaged wind conditions (frequency). Based on cumulative annual average exposure, considering all the different wind directions, trajectory 3 comes out to be the best with only $8.4 \%$ higher values than the baseline exposure. These are interesting results for policy makers to make a priority whether the average or peak exposure should be targeted as mitigation measures.

Choosing the best pedestrian paths, tracks, or roads for walking people is a generally overlooked aspect. Our results suggest that, if due attention is given, mitigation plans can be designed by local public authorities, municipalities, and decision makers to substantially cut down the exposure to children, elderly, and general public inside the busy street canyons.

\section{Conflict of Interests}

The authors declare that there is no conflict of interests regarding the publication of this paper.

\section{Acknowledgments}

The authors wish to acknowledge Comissão de Coordenação e Desenvolvimento Regional de Lisboa e Vale do Tejo (CCDR-LVT) and Instituto de Meterologia (IM) for the information provided.

\section{References}

[1] P. Kumar, S. Jain, B. R. Gurjar et al., "New Directions: can a "blue sky" return to Indian megacities?" Atmospheric Environment, vol. 71, pp. 198-201, 2013.
[2] WHO, Outdoor Air Pollution: Assessing the Environment Burden of Disease at National and Local Levels, World Health Organization, 2004.

[3] G. Davies and L. Reid, "Growth of the alveoli and pulmonary arteries in childhood," Thorax, vol. 25, no. 6, pp. 669-681, 1970.

[4] APHEIS, "Air Pollution and Health: a European Information System," Health Impact Assessment of Air Pollution and Communication Strategy, France, 2005, http://apheis.net/.

[5] EEA, "European Environment Agency, Environment and Health," EEA report 10/2005, Copenhagen, Denmark, 2005, http://www.eea.europa.eu/publications/eea_report_2005_10.

[6] EPA, Child-Specific Exposure Factors Handbook, U.S. Environmental Protection Agency, 2002.

[7] J. Pekkanen, S. T. Remes, T. Husman et al., "Prevalence of asthma symptoms in video and written questionnaires among children in four regions of Finland," European Respiratory Journal, vol. 10, no. 8, pp. 1787-1794, 1997.

[8] J. Schwartz, F. Laden, and A. Zanobetti, "The concentrationresponse relation between PM2.5 and daily deaths," Environmental Health Perspectives, vol. 110, no. 10, pp. 1025-1029, 2002.

[9] R. M. Harrison and J. X. Yin, "Particulate matter in the atmosphere: which particle properties are important for its effects on health?" Science of the Total Environment, vol. 249, no. 1-3, pp. 85-101, 2000.

[10] F. Wei, W. Hu, J. Teng, and R. S. Chapman, "Relation analysis of air pollution and children's respiratory system disease prevalence," China Environmental Science, vol. 20, no. 3, pp. 220-224, 2000.

[11] M. R. Heal, P. Kumar, and R. M. Harrison, "Particles, air quality, policy and health," Chemical Society Reviews, vol. 41, no. 19, pp. 6606-6630, 2012.

[12] K. L. Timonen and J. Pekkanen, "Air pollution and respiratory health among children with asthmatic or cough symptoms," American Journal of Respiratory and Critical Care Medicine, vol. 156, no. 2, pp. 546-552, 1997.

[13] B. B. Jalaludin, B. I. O'Toole, and S. R. Leeder, "Acute effects of urban ambient air pollution on respiratory symptoms, asthma medication use, and doctor visits for asthma in a cohort of Australian children," Environmental Research, vol. 95, no. 1, pp. 32-42, 2004.

[14] I. Galán, A. Tobías, J. R. Banegas, and E. Aránguez, "Shortterm effects of air pollution on daily asthma emergency room admissions," European Respiratory Journal, vol. 22, no. 5, pp. 802-808, 2003.

[15] L. A. Wallace, H. Mitchell, G. T. O'Connor et al., "Particle concentrations in inner-city homes of children with asthma: the effect of smoking, cooking, and outdoor pollution," Environmental Health Perspectives, vol. 111, no. 9, pp. 1265-1272, 2003.

[16] G. Ciccone, F. Forastiere, N. Agabiti et al., "Road traffic and adverse respiratory effects in children," SIDRIA Collaborative Group. Occupacional Environmental Medicine, no. 55, pp. 771778, 1998.

[17] A. Biggeri, M. Baccini, P. Bellini, and B. Terracini, "Metaanalysis of the Italian studies of short-term effects of air pollution (MISA), 1990-1999," International Journal of Occupational and Environmental Health, vol. 11, no. 1, pp. 107-122, 2005.

[18] C. Tonne, J. Yanosky, A. Gryparis et al., "Traffic particles and occurrence of acute myocardial infarction: a case-control analysis," Occupational and Environmental Medicine, vol. 66, no. 12, pp. 797-804, 2009. 
[19] L. Clancy, P. Goodman, H. Sinclair, and D. W. Dockery, "Effect of air-pollution control on death rates in Dublin, Ireland: an intervention study," The Lancet, vol. 360, no. 9341, pp. 1210-1214, 2002.

[20] R. D. Peng, F. Dominici, R. Pastor-Barriuso, S. Zeger, and J. M. Samet, Seasonal Analyses of Air Pollution and Mortality in 100 U.S. Cities, Berkeley Electronic Press, 2004.

[21] European Environment Agency (EEA), Air Quality in Europe2011 Report, European Environment Agency, 2011.

[22] P. Kumar, A. Robins, S. Vardoulakis, and R. Britter, "A review of the characteristics of nanoparticles in the urban atmosphere and the prospects for developing regulatory controls," Atmospheric Environment, vol. 44, no. 39, pp. 5035-5052, 2010.

[23] P. Kumar, M. Ketzel, S. Vardoulakis, L. Pirjola, and R. Britter, "Dynamics and dispersion modelling of nanoparticles from road traffic in the urban atmospheric environment-a review," Journal of Aerosol Science, vol. 42, no. 9, pp. 580-603, 2011.

[24] P. Kumar, B. R. Gurjar, A. S. Nagpure, and R. M. Harrison, "Preliminary estimates of nanoparticle number emissions from road vehicles in megacity Delhi and associated health impacts," Environmental Science and Technology, vol. 45, no. 13, pp. 55145521, 2011.

[25] SEPA, "Air pollution and chindren's respiratory health," Report 6353, Swedish Environmental Protection Agency, 2010.

[26] FLUENT, ANSYS Fluent 12.0, Theory Guide, ANSYS, 2009.

[27] CERC, ADMS-Urban, an Urban Air Quality Management System. User Guide-Version 2.2, CERC, Cambridge, UK, 2006.

[28] Omron, Industrial Automation Guide 2011, Omron Europe BV, 2011.

[29] J. Garcia, R. Cerdeira, N. Tavares, L. M. R. Coelho, P. Kumar, and M. G. C. Carvalho, "Influence of virtual changes in building configurations of a real street canyon on the dispersion of $P M_{10}$," Urban Climate, vol. 5, pp. 68-81, 2013.

[30] S. Di Sabatino, R. Buccolieri, B. Pulvirenti, and R. E. Britter, "Flow and pollutant dispersion in street canyons using FLUENT and ADMS-Urban," Environmental Modeling and Assessment, vol. 13, no. 3, pp. 369-381, 2008.

[31] S. Awasthi and K. K. Chaudhry, "Numerical simulation and wind tunnel studies of pollution dispersion in an isolated street canyon," International Journal of Environment and Waste Management, vol. 4, no. 1-2, pp. 243-255, 2009.

[32] COST, Best Practice Guideline for the CFD Simulation of Flows in the Urban Environment, Quality Assurance and Improvement of Microscale Meteorological Models, COST Action 732, 2007.

[33] P. J. Richards and R. P. Hoxey, "Appropriate boundary conditions for computational wind engineering models using the $\mathrm{k}-\varepsilon$ turbulence model," Journal of Wind Engineering and Industrial Aerodynamics, vol. 46-47, pp. 145-153, 1993.

[34] M. J. Brown, C. Muller, B. Bush, and P. Stretz, "Exposure estimates using urban plume dispersion and traffic microsimulation models," in Proceedings of the 10th Conference on Air Pollution Meteorology, Phoenix, Ariz, USA, January 1998.

[35] D. J. Moschandreas and S. Saksena, "Modeling exposure to particulate matter," Chemosphere, vol. 49, no. 9, pp. 1137-1150, 2002.

[36] WHO, Guidelines for Indoor Air Quality: Selected Pollutants, World Health Organization, 2010.

[37] J. N. P. M. Garcia, R. S. da Silva Cerdeira, N. A. Tavares, and L. M. R. Coelho, "Studying street geometry influence in $\mathrm{PM}_{10}$ concentration," International Journal of Environment and Pollution, vol. 50, no. 1-4, pp. 283-292, 2012. 

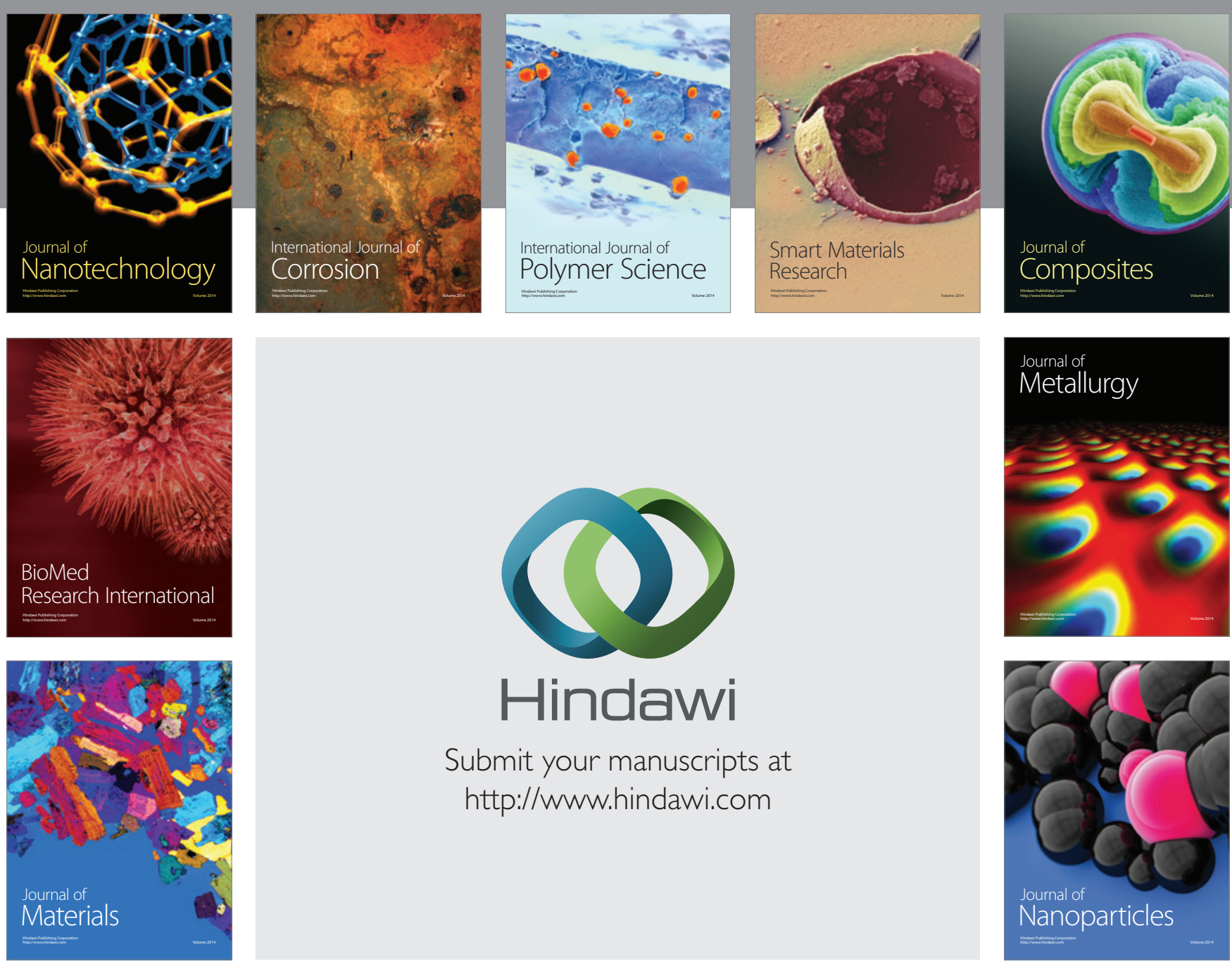

Submit your manuscripts at http://www.hindawi.com
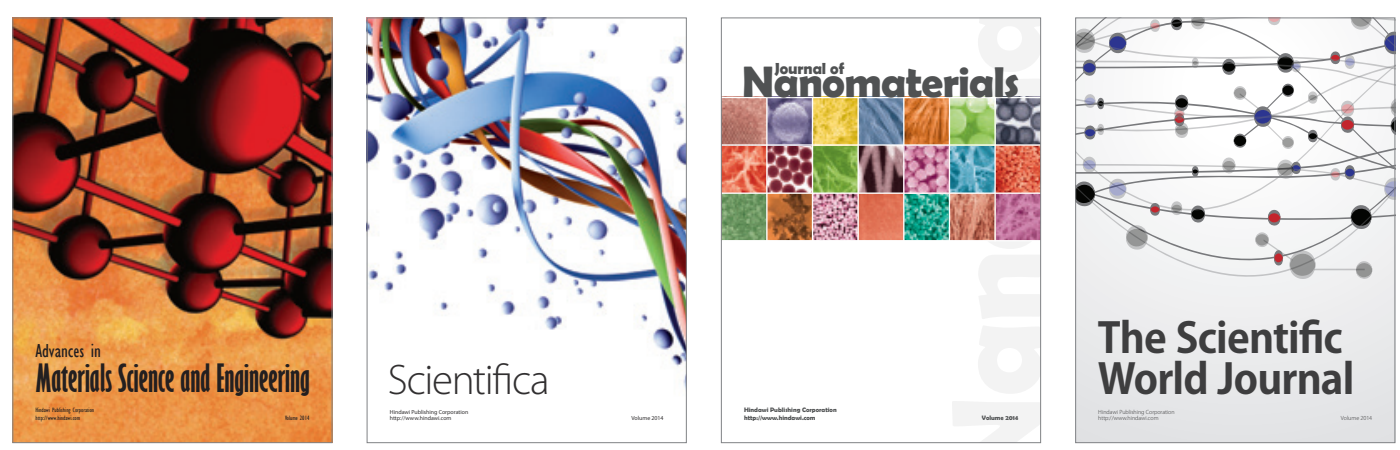

\section{The Scientific World Journal}
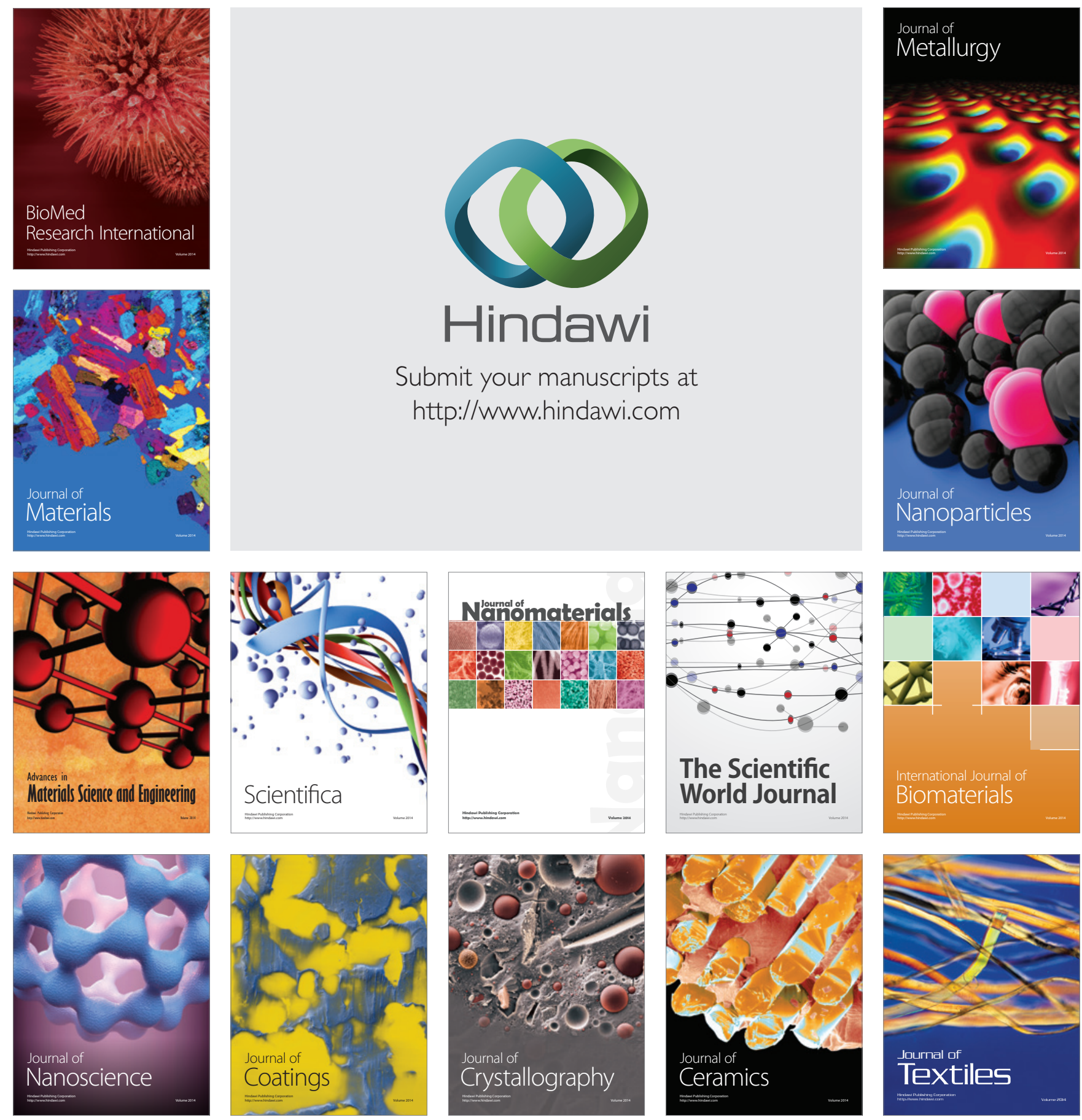